\title{
Uma nova espécie de Aspidosperma da Amazônia
}

\author{
Apparicio PEREIRA DUARTE(*)
}

Jardim Botânico do Rio de Janeiro

\begin{abstract}
SINOPSE
O autor apresenta neste trabalho a descrição de Aspidosperma williamsii A. P. Duarte, uma nova espécie de Apocynaceae da Flora Amazônica.
\end{abstract}

\section{Aspidosperma williamsii A. P. Duarte, n. sp.} (Figura 1: A-E)

Arbor ca. 30 metralis alta, $50 \mathrm{~cm}$ diametri ritidomate cinereo obscure lenticellosis, liber luteo sulfureo fibroso amaro. Ramuli fusco rufescentis, lenticellosis, estriatis angulosis, floriferis rufis rugosis. Folia alterna membranaceis oblongis-lanceolatis, acuminatis obtusis, basi cuneata acuta saepe inaequilatera; petiolis gracilis $10-22 \mathrm{~mm}$ longis supra canaliculatis usque $2 / 3$ ad basin pilis ferrugineis instructis, subtus estriatis plusminusve adpressis; lamina supra pallida nitida; subtus papillosa $5-11 \mathrm{~cm}$ longa et $2-3,3 \mathrm{~cm}$ lata, rachis prominulis angulosa striatis, nervis lateralis conspicuis saepe bifurcatis interdum insidentibus $70-80^{\circ}$, nervis secundariis ante marginem furcata ,16-17 jugis vel alterne vel suboposite. Inflorescentia paniculata-corymbosa, subterminalis haud axilaris; peciolis $2 / 3$ longiores, $2,5 \mathrm{~cm}$ alta et $4 \mathrm{~cm}$ diametro, pedunculis ramosis super insersionem $0,5 \mathrm{~cm}$ usque 4 semel; nigrescentis, rugosis, striatis, indumentum rufescentis, lobis latis, ovalis obtusis ca. $15 \mathrm{~mm}$ longis et $1 \mathrm{~mm}$ latis exteriora vailiosa intus, glabra. Corolla lutea exteriora dense peberula interiora villosa, glabrescens ad insersionem; tubo $4 \mathrm{~mm}$ longo et $2,5 \mathrm{~mm}$ lato. Stamina dimidium tubum inserta. Antherae sagitiforme apiculatae $1 \mathrm{~mm}$ longae et $0,5 \mathrm{~mm}$ latae. Ovarium dense villosum ca. $1,5 \mathrm{~mm}$ longum et $1 \mathrm{~mm}$ diametro, stylus $1,5 \mathrm{~mm}$ longus; stigma vix incrassatum $1,5 \mathrm{~mm}$ longum. Mericarpium (folliculos) ellipticum glabratum, constatum, estipitatum, verru culosum-palpilosum $9 \mathrm{~cm}$ longum et $7 \mathrm{~cm}$ diametro, ressupinatio ca. $45^{\circ}$, dehiscentia ventralis, marginis revolutis.

Árvore com cerca de $30 \mathrm{~m}$ de altura por $50 \mathrm{~cm}$ de diâmetro, ritidoma delgado, cinéreo, obscuro, lenticeloso, liber amarelo, sulfúreo, fibroso, amargo. Ramos foscos, avermelhados, lenticelosos estriados, angulosos, floríferos, rufos, rugosos. Folhas membranáceas, oblongolanceoladas, acuminadas, obtusas com a base cuneada, aguda, às vezes inequilatera; com os pecíolos gráceis, medindo de $10.22 \mathrm{~mm}$ de comprimento, canaliculado na face ventral até $2 / 3$ da base, provido de pelos ferrugíneos e estriados no dorso com ramos mais ou menos adpressos, limbo de cor pálida com a superfície dorsal papilosa, a ventral obscura, nítida, $5-11 \mathrm{~cm}$ de comprimento por $2-3,3 \mathrm{~cm}$ de largura, ráquis proeminente, anguloso, estriado, as nervuras la. terais conspícuas às vezes bifurcadas junto a margem formando ângulo de $70-80^{\circ} \mathrm{com}$ o ráquis, em número de 16-17 pares ora alternas ora subopostas. Inflorescência paniculada-corimbosa, não axilar, subterminal, $2 / 3$ do comprimento dos pecíolos, medindo $2,5 \mathrm{~cm}$ de altura por $4 \mathrm{~cm}$ de diâmetro, os pedúnculos se ramificam $0,5 \mathrm{~cm}$ acima da inserção até 4 vezes; nigrescentes, rugosos, estriados vestidos de esparso indumento ferrugineo, tornando-se mais denso na base dos pedicelos. Cálice revesti. do de indumento rufescente com os lobos largo-ovais, obtusos com $1,5 \mathrm{~mm}$ de comprimento por $1 \mathrm{~mm}$ de largura, densamente coberto de indumento rufescente viloso na face externa, glabro na interna. Corola creme densamente pubérula externamente, internamente de densos pelos vilosos só glabrescente na inserção com o cálice, medindo $4 \mathrm{~mm}$ de comprimento por $2,5 \mathrm{~mm}$ de largura. Estames inseridos no meio do tubo da corola, anteras sagitadas, api-

(*) - Bolsista do Conselho Nacional de Pesquisas. 


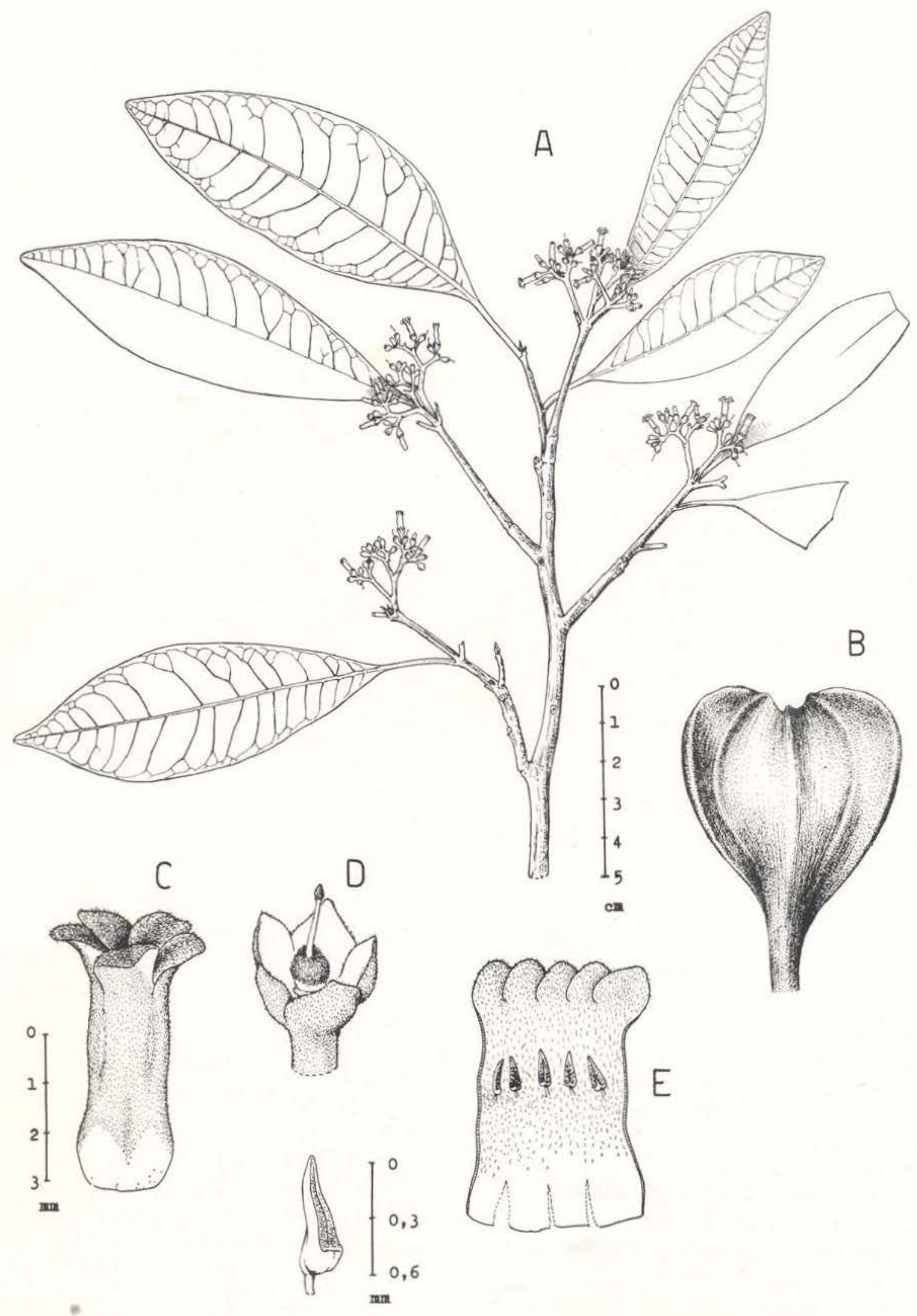

FIG. 1 - Aspidosperma williamsii A. P. Duarte, n. sp. $A-$ Hábito de um raminho florífero. $B-$ Fruto. $C-$ Corola. $D-$ Cálice e gineceu. $E$ - Corola seccionada mostrando a inserção dos estames e ao lado uma antera vista de perfil. (Desenhos de Júlio Dellome Filho) 
culadas com $1 \mathrm{~mm}$ de comprimento por $0,5 \mathrm{~mm}$ de largura. Ovario densamente viloso com cerca de $1,5 \mathrm{~mm}$ de comprimento por $1 \mathrm{~mm}$ de diâmetro, encimado por estilete capitado, medindo $1,5 \mathrm{~mm}$ de comprimento. Folículo elítico, glabro percorrido por uma costa média proeminente, glabro, nigrescente com a superfície verruculosa-papilosa, estipitado, medindo $9 \mathrm{~cm}$ de comprimento por $7 \mathrm{~cm}$ de diàmetro, com ressupinação de cerca de $45^{\circ}$, abrindo-se pela sutura ventral com revolução das margens.

Distribuição geográfica - Muito pouco freqüente na mata de terra firme, de solo argiloso, da estrada Manaus-Itacoatiara, Estado do Amazonas, Brasil.

Holotypus - Estrada Manaus-Itacoatiara, $\mathrm{Km} 64$, Reserva W. Egler. Arvore grande de $45 \mathrm{~cm}$ de diâmetro de fuste, de entrecasca amarela, grossa; tronco cilíndrico, sem látex aparente; gathos novos com manchas ferrugíneas; copa com folhagem nova; flores com corola verde pálida. Leg. William A. Rodrigues, 8938 em 10/9/1970. Herb. INPA, 28.313, amostra de madeira INPA X-4133.
Paratypi - Estrada Manaus-Itacoatiara, $\mathrm{Km} 70$, margem direita. Árvore de $30 \mathrm{~m}$ por $50 \mathrm{~cm}$ de diâmetro, ocasional na mata de terra firme; tronco cilíndrico com pequena sapopema na base; entrecasca amarelo-enxofre, amargosa, com látex branco escasso; frutificação abundante; frutos apanhados do chão. Leg. W. A. Rodrigues, 8791 em 25/3/1970. Herb. INPA 27971. - Ibidem. Árvore grande com látex branco, escasso, apenas nos galhos novos e foIhas; flores branco-amareladas. Exsicata obtida da mesma árvore anteriormente colhida com frutos velhos. Leg. W. A. Rodrigues, $8978 \mathrm{em}$ 20/10/1970. Herb. INPA 28364.

Esta espécie, no momento, ocupa posição incerta por falta de dados mais completos. Por tudo quanto pudemos observar não se enquadra nas Séries conhecidas para a flora da Hiléia.

Este novo "taxon" é dedicado a seu descobridor, o botânico William A. Rodrigues.

\section{SUMMARY}

Aspidosperma williamsii A. P. Duarte is described in this paper as a new species of Apocynaceae for the Amazonian Flora. It is a few frequent tree in the upland forest near Manaus, Brazilian State of Amazonas, collected by the botanist William A. Rodrigues. 